\title{
Choosing a place to grow. Importance of within-plant abiotic microenvironment for Yponomeuta mahalebella
}

\author{
Conchita Alonso \\ Estación Biológica Doñana, CSIC Apartado 1056, E-41080, Spain
}

Key words: within-plant heterogeneity, tent caterpillars, temperature, circular statistics, Lepidoptera, Yponomeutidae

\begin{abstract}
The caterpillars of Yponomeuta mahalebella Latr. (Lepidoptera: Yponomeutidae) are monophagous on Prunus mahaleb (Rosaceae) leaves. Adult females deposit eggs in batches, which determines larval gregarious behaviour. Coupled with gregarious behaviour, caterpillars spin silk tents within they will feed until pupation. Distribution of tents in the field, their effect in microenvironmental larval growth conditions and the consequences for adult body mass and survival of larvae were studied.

There was a significant trend for tents to be placed with a southward orientation. Within-plant tent orientation was related to the sun-shade pattern experienced, which was the main effect determining thermal differences between the inside and the outside of the tent. These differences appeared to affect larval growth and survival, with higher survival of larvae and heavier adults emerging from tents oriented to the south-east and east, respectively.
\end{abstract}

\section{Introduction}

Studies on the relationships between insect herbivores and their host plants have mainly focused on factors determining selection between species, and much less frequently on those affecting choices within species (see Karban, 1992). However, intraspecific differences in size (Forsberg, 1987; Doak, 1992), chemical composition (Bowers \& Stamp, 1992; Zangerl \& Berenbaum, 1993), or sexual expression (Boecklen et al., 1990) of host plants have also been reported to be important for herbivorous insects. Moreover, withinplant heterogeneity may also affect small herbivores (Schultz, 1983), both as their food and as the place where they develop (Juliano, 1988; Alonso \& Herrera, 1996). This may be particularly true for insects feeding on trees and shrubs, as the canopy structure provides different microclimates, by affecting wind exposure, temperature and incidence of radiation (Bernays \& Chapman, 1994), with potential consequences for larval development (Suomela \& Nilson, 1994).

Environment is also important for development and fitness of insect herbivores (Fritz, 1990; Suomela
\& Nilson, 1994). Studying abiotic conditions at the within-plant level permit us to test the hypothesis that the microenvironment influences the plant-insect interactions, as shown in other interactions between ectothermic insects and their food plants, (see Herrera, 1995). Microenvironment might be studied both as a cue for insects in host plant selection and as a factor influencing insect fitness at among- and within-plant levels. Determining which cues are used by the insects for selection of feeding places on these different scales would help us to understand why we find them feeding on specific sites and what are the consequences for both the host and the herbivore.

Sensory capabilities of herbivores to detect chemical plant cues (Jermy, 1993; Bernays \& Wcislo, 1994), and their ability to avoid natural enemies (Bernays \& Graham, 1988; Ohsaki \& Sato, 1994) have been proposed as determinants of the host range and preference for different plant species. Abiotic factors have been considered less frequently; temperature has been studied as a factor interacting with food quality to determine foraging behaviour (Stamp \& Bowers, 1990; Stamp, 1993) but mostly as a factor acting after selec- 
tion, rather than as an influential factor by itself (but see Williams, 1981; Forsberg, 1987). The sunny or shaded situation of host plants has been related to insect abundance (Maiorana, 1981; Lincoln \& Mooney, 1984) but mostly considered as a factor influencing food quality (Dudt \& Shure, 1994), rather than clearly described as a cue for selecting development places (but see Moore et al., 1988).

The relationship established between caterpillars of Yponomeuta mahalebella and their food plant Prunus mahaleb is particularly interesting because these caterpillars are not very mobile and therefore, they may experience variation at within-plant level. Thus, their feeding site, selected primarily at oviposition, will be important to determine microenvironmental conditions for larval development. In addition, by spinning a silk tent, the small ermine moth caterpillars alter the microclimatic conditions during the larval growth period (Knapp \& Casey, 1986; Joos et al., 1988) as these tents bring out thermal heterogeneity within the tree crown.

The aim of this work was to determine if the thermal component of microclimate could be related to $Y$. mahalebella feeding site selection, focusing on thermal heterogeneity within individual host plants. The effects of microclimate on larval growth and survival have also been evaluated. The specific questions addressed in this paper are: Are P. mahaleb canopies homogeneous from the viewpoint of $Y$. mahalebella?. If they are not, are then abiotic factors related to heterogeneity? And are these herbivores able to select the

best places to develop? Are there any consequences of this selection for insect growth and survival?

\section{Materials and methods}

Observations were carried out in 1994, between April 11 and June 30, in two P. mahaleb populations located in the Sierra de Cazorla (Jaén province, southeastern Spain).

Study sites. The main study site, Poyo Manquillo (PM) was located at $1450 \mathrm{~m}$ elevation. About one third of the trees in this area were growing on a 45 northwest slope while the others were on a level surface. During the 10-wk study period, average air temperatures varied between 5.1 C and 27.3 C (means of weekly minimum and maximum temperatures), with extreme records of $1 \quad \mathrm{C}$ and $32.5 \quad \mathrm{C}$. The second site, Torcal del Cerecino (TC), having a larger P. mahaleb population, was located at $1530 \mathrm{~m}$ elevation, and all the trees grew there on a 40 east slope. Temperatures at this site ranged on average between $3.9 \quad \mathrm{C}$ and

23.6 C during the study interval, with extreme records

of $-5 \quad \mathrm{C}$ and $29 \quad$ C. The differences between weekly maximum and minimum temperatures in both popula- tions were not statistically significant during the 10 -wk study period.

Study organisms. P. mahaleb is a small deciduous tree growing in scattered populations in the Sierra de Cazorla. This species has not a clear apical dominance, which leads to a roughly spherical crown in most individuals. In the two study populations leaf flush began in early April, a few days before flowering, but leaves were not completely expanded until late May. The main foliage feeding insect on $P$. mahaleb in the study area were $Y$. mahalebella caterpillars.

In late summer, females of $Y$. mahalebella deposit egg masses around the stems of their specific host plant P. mahaleb (Kooi, 1990). Eggs hatch before hibernation and the first instar larvae remain inside the egg batch shelter until the next spring. Caterpillars live gregariously until pupation. In 1994, when this study was carried out, the low density of $Y$. mahalebella populations precluded finding egg masses before eclosion. Larvae were first observed at the PM site on April 22, 10 days after the sample monitoring began, when they were feeding as miners inside expanding $P$. mahaleb leaves. From the second instar on, they spun a conspicuous silk tent close to the place in which they had been first found, living in groups of 14 11, (mean SD; this notation will be used henceforth unless otherwise stated), ( $n=34$ groups). These larval aggregations decreased in size over the growth period due to subdivision into smaller groups and death of individual larvae. By the end of the season, when caterpillars began to go down the tree to pupate, mean number of individuals per group was 54 , $(n=105$ collected groups), several groups having originated in the same tent.

Methods. Before there was any sign of herbivory on any tree, I marked all 28 P. mahaleb trees existing at $\mathrm{PM}$, and 20 randomly selected ones at TC, which were subsequently monitored weekly for insect herbivores. All $Y$. mahalebella tents found on them were marked using numbered coloured plastic tape. The orientation of the major (usually longitudinal along a stem) axis of tents with respect to the tree trunk were determined by compass. Tents built along the uppermost branches 
(and thus vertically oriented) were excluded from the analyses ( $n=4$ tents). On June 22 all tents containing living caterpillars were collected and placed into plastic bags until moths or parasitoids emerged. Adults moths were killed, dry weighed and sexed. Parasitoid incidence per tent was evaluated as the proportion of collected individuals in which parasitoids had developed. Although there are some methodological problems with estimation of parasitoid incidence from field collections (Van Driesche et al., 1991), it is unlikely that parasitized larvae changed behaviour, as it has not been reported for the same parasitoid species in other Yponomeuta sp. (Dijkerman et al., 1986; Kuhlman, 1995; S.B.J. Menken et al., pers. comm.).

The consequences of microclimate conditions on Y. mahalebella potential fitness, were analyzed using larvae inside tents collected from marked trees at the end of the growing season. Percentages of these larvae reaching the adult stage were used as survival estimator and their adult body mass as estimator of potential fecundity.

Observational data. Instantaneous air temperature inside and outside every marked tent at PM site were recorded by using a $0.5 \mathrm{~mm}$ diameter Type $\mathrm{T}$ thermocouple, connected to a digital thermometer. It was inserted into the zone of the tent where most larvae were located, this did not alter the tent structure but the caterpillars usually moved elsewhere in the tent. Thus, temperature recorded inside the tent $\left(T_{\text {int }}\right)$ was not affected by a possible contact of the thermocouple by the larvae. External temperature $\left(T_{\text {ext }}\right)$ was recorded shortly after the internal one, by placing the same thermocouple about $1 \mathrm{~cm}$ from the tent. Measurement series began at 10:00 $\mathrm{h}$ and were made in a different order each time. Time of day and whether the tent was in the sun or shade at the time of observation, were also recorded on each occasion. A total of 301 paired internal-external records were obtained. Difference of temperatures $\left(T_{\text {dif }}\right)$, which represents the thermal effect of the tent, was obtained for each sample by computing the difference $T_{\text {int }}-T_{\text {ext }}$. Temperature data were collected weekly between May 13, when there were 34 marked tents, and June 9, when there were 77 marked tents.

As air temperature varies during daytime, one would expect time of measurement to influence both $T_{\text {int }}$ and $T_{\text {ext }}$, but not necessarily its difference. Thus, the daily pattern of temperature variation would be more illustrative than instantaneous measures to evaluate the thermal effect of the tent. Therefore, I selected two tents in the same tree and recorded internal and external temperatures automatically at 1-min intervals during $25.5 \mathrm{~h}$, connecting thermocouples to a datalogger. They were selected at opposite directions (eastwest) to obtain a preliminary idea of the effect of being at different orientations.

Experimental data. An experiment was carried out to test for the influence of tent orientation on thermal conditions after controlling the effects of tent characteristics. Two empty tents were taken from an unmarked tree (by cutting the branches in which they have been spun), attached to a stick where one thermocouple could be placed inside each tent and another one outside. The whole assembly was placed in a branch, at 180 south with respect to the tree trunk. Temperatures inside and outside both tents were recorded simultaneously at 1min intervals for $20 \mathrm{~min}$. This procedure was repeated for the four main compass directions, taking about $2 \mathrm{~h}$ to complete the series. I repeated the complete trial 6 times between 10:30 and 21:10 $\mathrm{h}$ on the same day.

Data analysis. Individual tents have been used as sampling units because $Y$. mahalebella larvae grow in clusters from egg oviposition until pupation, thus representing real biological entities. There was no evidence of first instar larvae moving far away from the place in which they hatched, as has been also found for other tent caterpillars (Moore et al., 1988). Furthermore, in all the cases in which I found early-season aggregations of 1st-instar larvae, the tent was subsequently spun within a few centimeters of the original location. Therefore, the place in which caterpillars begin to spin the tent is determined at oviposition time and affects similarly all the larvae of the group. Moreover, caterpillars living together develop under the same microenvironmental conditions determined by maternal selection at oviposition and by the features of the tent they build together. Thus, individual larvae are not independent from the others in the same tent, neither biologically nor statistically. When initial groups split into smaller subgroups and it was possible to determine which was the original tent, all the subgroups were considered together as a sampling unit.

To test if there was any trend in tent location in both study populations, tent orientation data determined by compass were analyzed as a circular variable (Batschelet, 1981), assuming northwards orientation to be 0 and the $P$. mahaleb crown to be a circle. The Rayleigh test was applied to calculate the significance of the angular mean orientation of the tents, and 
the non-parametric Mardia-Watson-Wheeler statistic to test whether location of the tents in both populations differed in the mean angle, in the angular variance or in both (Batschelet, 1981). Correlates between tent orientation and the linear variables adult body mass and percentage of survival larvae per tent, were analyzed only for PM site due to an insufficient sample size at the TC site. They were analyzed with a rank correlation method proposed by Mardia (Batschelet, 1981), in which the $D$ statistic represents a correlation index between a circular and linear variables. The significance level was computed using randomization methods (Noreen, 1989; Manly, 1991) with 10000 repetitions. I used macro language of SAS System (SAS Institute, 1989) to compute circular analyses except the Rayleigh test that was made using the program Oriana for Windows, version 1.01 (Kovach Computing Services, Pentraeth, UK).

When the same biological hypothesis was tested on different sets of data and inference about results was not obvious (the hypothesis was rejected when based on certain data sets, but was not when based on other data sets), I used the Fisher test (Sokal \& Rohlf, 1981) to combine the probabilities obtained and be able to conclude about their global significance.

Paired-temperature data collected simultaneously were analyzed using the paired $t$-test (Proc MEANS, SAS Institute, 1989) to test if Tdif was statistically significant. Significance of other factors (e.g. sunlit/shaded location, experimental orientation, time of

day) on temperatures was tested using ANOVA tests (Proc GLM, SAS Institute, 1989). In each test, it will be noted for each factor whether it will be considered fixed or random (Bennington \& Thayne, 1994).

\section{Results}

Tent orientation. A total of 138 Y. mahalebella tents were observed and their orientation determined on the 28 trees at PM during the study period. However, some of them $(\mathrm{N}=32)$ could not be marked nor their larvae collected due to difficulties in reaching them.

Tents were neither randomly nor uniformly distributed within trees with regard to orientation. Significant directionality existed in 6 of the 10 study plants which had more than the mean number of tents per tree (Table 1). The remaining 4 trees did not have any obvious distinctive feature that could explain the failure to obtain significant results. Combining probabilities from the 10 individual tests I rejected the null
Table 1. Mean orientation of Y. mahalebella tents in $P$. mahaleb trees with 6 tents. Significance of directionality was tested using the Rayleigh test for circular variables. Significant orientations are shown in bold type

\begin{tabular}{lclr}
\hline $\begin{array}{l}\text { Tree } \\
\text { No. }\end{array}$ & $\begin{array}{l}\text { Number } \\
\text { of tents }\end{array}$ & $\begin{array}{l}\text { Mean } \\
\text { orientation } \\
\text { (deg) }\end{array}$ & \\
\hline 750 & 6 & 175.3 & 0.08 \\
746 & 7 & $\mathbf{2 8 0 . 6}$ & $<0.01$ \\
742 & 8 & 155.8 & 0.77 \\
755 & 8 & $\mathbf{1 4 4 . 2}$ & 0.01 \\
745 & 9 & $\mathbf{2 0 3 . 2}$ & $<0.01$ \\
749 & 10 & $\mathbf{5 6 . 6}$ & 0.01 \\
738 & 11 & $\mathbf{1 4 0 . 8}$ & $<0.01$ \\
733 & 12 & 127.8 & 0.22 \\
744 & 13 & $\mathbf{2 4 0 . 2}$ & 0.02 \\
740 & 15 & 219.5 & 0.88 \\
\hline
\end{tabular}

hypothesis of no directionality in tent orientation within trees ( ${ }_{20}=62.7, \mathrm{P} \quad 0.0001$; Fisher test $)$ in this population.

When tents from all trees in the same population were combined into a single sample, a significant trend ( $\mathrm{P}<0.01$; Rayleigh test in both populations) emerged for them to be predominantly found on southfacing parts of the trees. (Figure 1). This trend was not significantly different between populations ( $W=4.9$, $\mathrm{P}=0.087$; Mardia-Watson-Wheeler test) with a mean angular orientation $\quad$ SE of $181.1 \quad 16.0$ and 195.5 19.2 at PM and TC ( $n=26$ tents) sites, respectively. Thus, Y. mahalebella appears to discriminate between different sides of the trees for developing, at least in 1994 when caterpillars were found growing preferentially on the south-facing part of the host trees in the study area.

Microclimate effects. Tents provided larvae with a warmer microenvironment for development. $T_{\text {int }}$ and $T_{\text {ext }}$ measured in marked tents differed significantly ( $n$ $=301, t=16.4, \mathrm{P}<0.0001$; paired $t$-test), being higher inside the tent with a $T_{\text {dif }}=2.3 \quad 2.4 \quad \mathrm{C}$.

$T_{\text {dif }}$ was significantly affected by the insolation status (sunlit vs. shaded, Figure 2) of the tent at the time of measurement $\left(F_{1 ; 299}=129.4, \mathrm{P}-0.0001\right.$; insolation status treated as a fixed effect) and this factor alone explained $30 \%$ of variance in $T_{\text {dis }} . T_{\text {int }}$ was on average 3.7 C higher than $T_{\text {ext }}$ when sunlit and only 1 C when shaded. Daytime also had a significant effect on $T_{\text {dif }}$, but its effect differed between sunlit (when it 
PM site

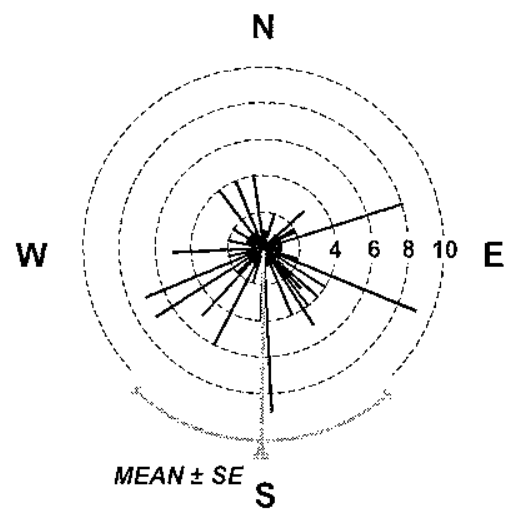

TC site

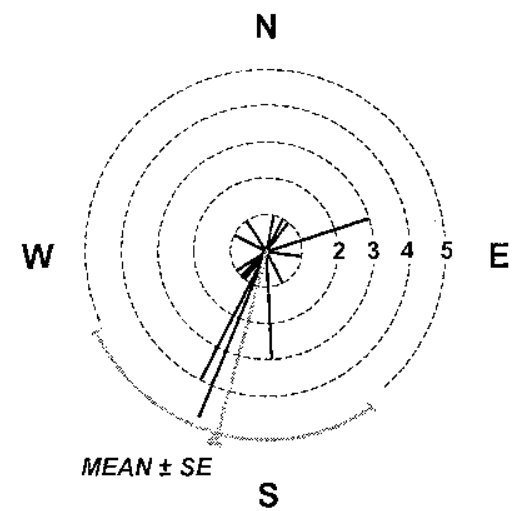

Figure 1. Orientation relative to Prunus mahaleb tree trunks of all observed Yponomeuta mahalebella tents. Each segment is located in different compass directions and its length represents the number of tents (numeric scale on concentric rings) observed in this orientation. Mean orientations ( SE) are indicated by shaded segments. Sample size are $n=138$ and 26 tents in PM and TC sites, respectively.

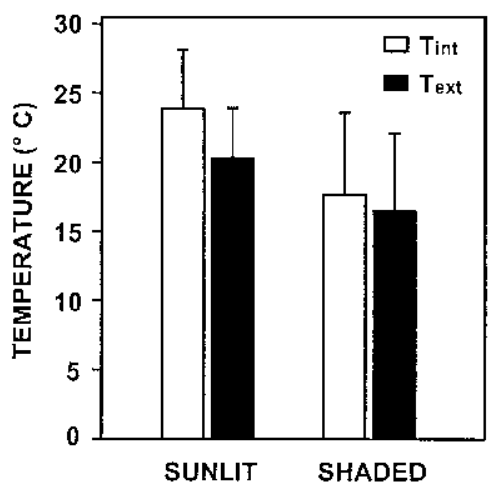

Figure 2. Effect of insolation status and orientation of the tents on temperatures recorded inside $\left(T_{\text {int }}\right)$ and outside $\left(T_{\text {ext }}\right)$ Yponomeuta mahalebella tents. Bars represent average values and vertical segments extend over 1 SD. Data for all marked tents at PM site, recorded between 10 and $21 \mathrm{~h}$ on different dates ( $n=301$ measurements).

explained about $5 \%$ of variance) and shaded conditions (when it explained about 18\%). This suggested that the daily sun/shade pattern experienced by a tent might be important to determine the 'rearing temperature' of caterpillars in its interior.

Preliminary results obtained from the continuous monitoring of temperatures at two tents located at opposite orientations on the same tree, provided further evidence suggesting a role of radiation. The effect of the tent was not the same in different locations around the tree crown when daily variation was considered (Figure 3). During daytime (between 8:30 and 19:30 h), $T_{\text {int }}$ of the two tents located at opposite east-west directions differed significantly $(\mathrm{P}<0.0001$; Student $t$

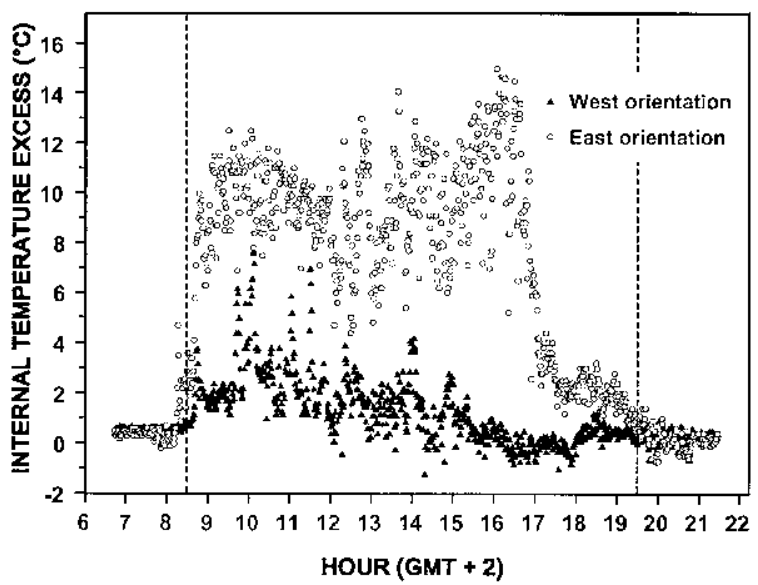

Figure 3. Daily variation in internal temperature excess, i.e., difference between internal and external tent temperature $\left(T_{\text {dif }}\right)$, recorded simultaneously at 1-min intervals in two different Yponomeuta mahalebella tents located at opposite east-west orientations of the same tree. Dashed vertical lines indicates local sunrise and sunset times.

test) by as much as 7.3 4.1 $\quad$ C. There was also a significant difference in $T_{\text {ext }}(\mathrm{P}<0.0001$; Student $t$ test), although the mean difference between both was only $0.7 \quad 1.3 \quad$ C. Consequently $T_{\text {dif }}$ differed significantly as a result of tent orientation $(\mathrm{P}<0.0001$; Student $t$ test. Figure 3), averaging $6.5 \quad 3.4 \quad \mathrm{C}$ between the east and west locations. No differences were found between thermal conditions of both tents during the night (between 19:31 and 8:29 h).

This result should be interpreted with caution, as different tents were involved and the observed contrast 
Table 2. Temperatures recorded inside $\left(T_{\mathrm{int}}\right)$ and outside $\left(T_{\mathrm{ext}}\right)$ tents and their differences $\left(T_{\text {dif }}\right)$. Data from simultaneous measurements into two different empty tents put successively in the four main compass directions of the same tree during the day. Means corrected by repetition's effect. Different letters in the same column showing significant differences between orientations (Student-Newman-Keuls test, $\mathrm{P}<0.05$ )

\begin{tabular}{lllllll}
\hline Orientation & $n$ & \multicolumn{2}{c}{ Means tent \# 1 } & \multicolumn{2}{l}{ Means tent \# 2 } & \multirow{2}{*}{$T_{\text {ext }}$} \\
\cline { 3 - 6 } & & $T_{\text {int }}$ & $T_{\text {dif }}$ & $T_{\text {int }}$ & $T_{\text {dif }}$ & \\
\hline South & 113 & $27.74^{\mathrm{a}}$ & $4.14^{\mathrm{a}}$ & $25.65^{\mathrm{a}}$ & $2.09^{\mathrm{a}}$ & $23.53^{\mathrm{a}}$ \\
East & 126 & $25.55^{\mathrm{b}}$ & $2.35^{\mathrm{b}}$ & $24.84^{\mathrm{b}}$ & $1.59^{\mathrm{b}}$ & $23.39^{\mathrm{a}}$ \\
North & 117 & $25.23^{\mathrm{b}}$ & $2.15^{\mathrm{b}}$ & $24.68^{\mathrm{b}}$ & $1.55^{\mathrm{b}}$ & $23.06^{\mathrm{b}}$ \\
West & 122 & $24.28^{\mathrm{c}}$ & $1.33^{\mathrm{c}}$ & $23.88^{\mathrm{c}}$ & $0.95^{\mathrm{c}}$ & $22.95^{\mathrm{b}}$ \\
\hline
\end{tabular}

between orientations in thermal conditions could have been influenced by subtle differences between tents in structure, characteristics of the silk material or position relative to height above the ground. The observations were relevant to show a pattern, suggesting the importance of orientation for thermal conditions where larvae developed, but not to conclude about the magnitude of the results. These problems were solved with an experimental design in which the same tents were repeatedly placed in exactly the same sites, to test for orientation influence in tent thermal conditions.

Results from experimental design showed that the two tents, located close to each other, had statistically significant differences in $T_{\text {int }}$ recorded simultaneously ( $\mathrm{P}<0.0001$; Student $t$ test. Table 2). However, the mean difference between them was $0.9 \quad 2.4 \quad$ C and

explained less than $3 \%$ of variance in $T_{\text {int }}$ when tent was considered as a random effect in the linear model. Thus, although the particular structure of each tent could influence temperature recorded inside it, thermal differences of about $1 \quad \mathrm{C}$ may not be decisive for larvae development, although further data would be necessary to reach a firm conclusion about this.

Time of day and tent orientation had a more evident influence on the internal temperature of the tent. Time of day was analyzed as a class variable (repetition hereafter) considering each repetition as the variable level. Data were treated with a split-plot design, useful when more information is needed for comparing the levels of one factor (orientation) than for the other (time) (Mead, 1988; Littell et al., 1991). The model was highly significant $(\mathrm{P}<0.0001)$ and explained $63 \%$ of variance in $T_{\text {dif }}$ (Table 3 ). Both repetition and orientation had
Table 3. Split-plot ANOVA results for the effects of orientation and repetition on difference between internal and external temperatures $\left(T_{\text {dif }}\right)$. All factors were treated as fixed effects. Data recorded at two empty $Y$. mahalebella tents, put close to each other and located successively at each of the four main compass directions. Temperatures were recorded simultaneously at 1-min intervals during $20 \mathrm{~min}$ at each orientation

\begin{tabular}{lrrr}
\hline Source & DF & F Value & P value \\
\hline Tent & 1 & 72.19 & $<0.0001$ \\
Repetition & 5 & 7.21 & 0.0245 \\
Tent repetition & 3 & 15.02 & $<0.0001$ \\
Orientation & 3 & 66.25 & $<0.0001$ \\
Repetition orientation & 15 & 49.35 & $<0.0001$ \\
Error & 955 & & \\
\hline
\end{tabular}

a significant effect on $T_{\text {dif }}$, and their interaction was also highly significant. Therefore $T_{\text {dif }}$ varied during the day and this variation depended on tent orientation. There was also an overall orientation effect. Mean $T_{\text {dif }}$ in the southward orientation was significantly higher $(\mathrm{P}<0.0001)$ than at any of the other three directions (Table 2). This means that, on sunny days, larvae living in south-facing tents (the most frequent situation in the study area, as shown above), experienced significantly higher average temperatures than those located at other orientations. Then selection of a sunlit orientation

affected larval growth conditions and this effect was mainly a consequence of living inside a tent, whose structure enhanced thermal differences between orientation.

Potential fitness consequences. When larvae reached the last instar, most groups became subdivided into smaller aggregations, and each one of which spun a different, independent tent. For this reason, only caterpillars which could be confidently associated with an original tent, were gathered. The orientation of the 19 tents collected at the end of the growing season did not differ significantly from that for the whole population ( $W=0.5, \mathrm{P}=0.77$; Mardia-Watson-Wheeler test), and thus may be used as an unbiased subsample for testing the effects of orientation on larval survival and adult body mass. 
Effects on survival. Fifty-one percent of caterpillars reached the adult stage and those that failed to do so were either parasitized (25\%) or died from unknown causes (24\%). The Hymenoptera Ageniaspis fuscicollis Dalman (Encyrtidae), Baryscaptus evonymellus Bouché (Eulophidae, Tetraschinae) and Diadegma sp. (Ichneumonidae) were the main parasitoid species emerged from $Y$. mahalebella caterpillars reared in bags.

There was a statistically significant correlation between tent orientation and the proportion of larvae giving rise to adults $(D=0.99, \mathrm{P}=0.0001$; Mardia test). To determine the meaning of this correlation tents were split into two subgroups based on their survival, both classes were established taking tents from below and above the median percentage of survivors. Orientation of tents in both classes differed significantly ( $W=11.7, \mathrm{P}=0.0029$ ). Tents with a relative higher survival presented a significant south-east orientation (mean $133, \mathrm{P}<0.01$; Rayleigh test) and tents with a percentage of survivors below the median presented a significant west orientation (mean $286, \mathrm{P}<0.01$; Rayleigh test). Thus differential orientation of tents around the tree had measurable consequences in terms of larval success in development.

Effects on adult body mass. Adult males and females of $Y$. mahalebella differed significantly in body mass $\left(F_{1 ; 187}=109.3, \mathrm{P}-0.0001\right)$ with females being heav-

ier (11.7 $4.0 \mathrm{mg}$ dry weight, $n=81)$ than males (8.4 $2.9 \mathrm{mg}, n=108$ ). Thus, correlates between tent orientation and mean body mass of adults grown inside it were tested using the residuals of the linear model adult body mass $=$ sex + error, to account for possible artifacts derived from sex-biased ratios and to not reduce the sample size.

After controlling for the effect of sex, there was a significant correlation between tent orientation and the mean body mass of adults $(D=1.48, \mathrm{P}<0.0001, n=19$ tents; Mardia test). Tents were split into two subgroups, those with adults whose mean mass fell below and above the median. Orientation of tents in both classes differed significantly $(W=6.3, \mathrm{P}=0.04$; MardiaWatson-Wheeler test). The heaviest adults emerged from tents occurring in eastern orientations (mean = 102.6 ), and the lightest ones from those facing west (mean $=250)$.

\section{Discussion}

Larval gregariousness has evolved many times among butterflies and moths (Tullberg \& Hunter, 1995). Natural enemies have been reported as the main selective force acting after the evolution of aposematism (warning colouration and unpalatability) to select gregariousness in Lepidoptera. Constraints on ovipositing females, related to distribution and abundance of the host plant, particularly in temperate areas (Stamp, 1980), and constraints on nutrition of larvae, related to complete defoliation of the food plant, could determine the optimum size of the group (Sillén-Tullberg \& Leimar, 1988).

Gregariousness provides other advantages to eggs and larvae (Stamp, 1980). Thermoregulation may be one of the main advantages for those gregarious larvae living in temperate regions that, like other ectotherms, depend on external heat sources to elevate their body temperature. Living gregariously Y. mahalebella larvae spin a silk tent that reach up to 11.4 C over the surrounding air temperature when fully insolated (see Joos et al., 1988, for similar findings in other tent caterpillars). This thermal difference could affect larval development, especially when maxima temperatures in the warmest $P$. mahaleb sites in the study area, barely reached the lower limit for the reported optimal growth temperatures of Lepidoptera, ranging from 27.2 to $37.7 \quad$ C (Taylor, 1981). Therefore, slight increases

of temperature could affect the rate of development (Casey, 1993), and final body mass and/or duration of the larval period may be modified with fitness consequences (Knapp \& Casey, 1986).

As insolation has been observed to be essential in determining the difference between inside and outside the tent (Figure 2), and orientation is closely related to insolation, then selection of a good feeding site for the offspring in relation to orientation can affect fitness of ovipositing females, at least when there are no other factors (e.g. overcrowding) forcing larvae to move away from their initial place. Orientation has been reported to be important for survival and growth of larvae in other species (Grossmueler \& Lederhouse, 1985; Suomela et al., 1995a). The first evidence supporting this hypothesis was the directionality of tent location (Table 1). Moreover, this study shows that Y. mahalebella caterpillars were preferentially located in the south side of tree crowns (Figure 1) where they were exposed to direct irradiance for longer periods the other three main compass directions (Table 2). 
and \&experienced higher temperatures than in any of

the other three main compass directions (Table 2). 
Thus, $P$. mahaleb trees were not homogeneous from the small ermine moth viewpoint. Another tent species Malacosoma californicum pluviale shows the same within-plant distribution pattern (Moore et al., 1988). These authors did not find evidence for a relationship between larvae orientation and food quality. There may be, however, other within-tree correlations of orientation in addition to insolation intensity, such as leaf phenology, leaf characteristics (e.g. Ganzhorn, 1995; Suomela et al., 1995b), architectural traits (Price et al., 1995), or differential wind exposition. One or several of these factors, which have not been considered in this study, could also contribute to female and/or larvae selection. Results shown in this paper point to the sun-shade pattern also as a suitable cue for $Y$. mahalebella females searching oviposition places as reported for other lepidopteran species (Williams, 1983) or at least like a potential selection pressure for caterpillars.

Survival of larvae was correlated to tent orientation with tents located in south-east orientation reaching higher survival rates. There was no significant relationship between orientation and the proportion of parasitized larvae or 'dead' larvae in the tent. Thus, the effect of orientation in survival was not directly related to parasitoid success, e.g. affecting parasitoid behaviour as reported for other species (Kuhlmann, 1995). It could be that caterpillars from tents in south-east orientation presented higher vigour because of better developmental conditions, but more data are needed to test this hypothesis.

The other potential fitness consequence considered was the effect on adult body mass. It has been reported that the relationship between size and fecundity could be affected by other physiological (Leather, 1988) and ecological factors (Boggs, 1990; Nylin et al., 1996). In this respect it may be useful to compare potential fecundity among individuals from different tents because all individuals were put in the same conditions after collection and none of the females had been fertilized nor had oviposition been observed before weighing. Moreover, another species of the same genus, Y. evonymella, has been reported to show a very good relationship between size of adult females and fecundity (Kooi et al., 1989; Leather \& Mackenzie, 1994). Thus, a relationship was found between tent orientation and mean adult body mass, with heavier adults emerging from tents with an eastern orientation. A thorough study is needed to evaluate the consequences in terms of realized fitness, including the success in first generation reproduction (Nylin et al., 1996).
To sum up, discrimination within individual host plants may be important when we focus on the herbivore's side of the interaction. Although in 1994 Y. mahalebella was not very abundant and therefore was impossible to observe egg batches on the trees, the location of larvae at the beginning of the season, when they were not very mobile, apparently indicated that eggs were deposited throughout the south side of the tree crowns (Figure 1). There, groups of larvae at south orientation had higher survival, whereas individuals from those oriented to the east were heavier and potentially more fertile. Within-tree heterogeneity in microenvironmental conditions seems to play an essential role in the plant-herbivore relationship studied, both by providing cues used by insect females during oviposition and influencing on the developmental success of their offspring.

On the other side of the interaction, if herbivory is consistently occuring in specific places of the tree crown (e.g. south side), this could increase within-tree variability (Haukioja, 1991) and differentially affect reproduction and growth of individual branches (Marquis, 1988) or Integrated Physiological Units (Watson, 1986) within the plant. More studies are required to conclude which are the effects of this pattern over the plant.

\section{Acknowledgements}

I am very grateful to Carlos M. Herrera for his suggestions and help during the field work, and his patience during the writing of this paper. Manolo Carrión, Rocío Requerey and Alicia Prieto provided me with assistance. M. Jesús Verdú and Jesús Selfa determined Hymenoptera specimens. Marie-Charlotte Ansttet, Carlos M. Herrera, Pedro Jordano, José Luis Yela and two anonymous reviewers gave valuable suggestions on drafts of the manuscript. The Agencia de Medio Ambiente authorized this work in Cazorla and provided invaluable facilities. This research was supported by DGICYT grant PB91-0114 to C. M. Herrera and a predoctoral fellowship from the Ministerio de Educación y Ciencia to the author.

\section{References}

Alonso, C. \& C. M. Herrera, 1996. Variation in herbivory within and among plants of Daphne laureola (Thymelaeaceae): correlation with plant size and architecture. Journal of Ecology 84: 495-502. 

Batschelet, E., 1981. Circular Statistics in Biology. Academic Press, London.

Bennington, C. C. \& W. V. Thayne, 1994. Use and misuse of mixed model analysis of variance in ecological studies. Ecology 75 : 717-722.

Bernays, E. A. \& R. F. Chapman, 1994. Behavior: the importance of ecology and physiology. In: E. A. Bernays \& R. F. Chapman (eds), Host-plant Selection by Phytophagous Insects. Chapman \& Hall, New York, pp. 166-205.

Bernays, E. A. \& M. Graham, 1988. On the evolution of host specificity in phytophagous arthropods. Ecology 69: 886-892.

Bernays, E. A. \& W. Wcislo, 1994. Sensory capabilities, information processing and resource specialization. Quarterly Review of Biology 69: 187-204.

Boecklen, W. J., P. W. Price \& S. Mopper, 1990. Sex and drugs and herbivores: sex biased herbivory in arroyo willow (Salix lasiolepensis). Ecology 71: 581-588.

Boggs, C. L., 1990. A general model of the role of male-donated nutrients in female insects' reproduction. The American Naturalist 136: 598-617.

Bowers, M. D. \& N. E. Stamp, 1992. Chemical variation within and between individuals of Plantago lanceolata (Plantaginaceae). Journal of Chemical Ecology 18: 985-995.

Casey, T. M., 1993. Effects of temperature on foraging caterpillars. In: N. E. Stamp \& T. M. Casey (eds), Caterpillars: Ecological and Evolutionary Constraints on Foraging. Chapman \& Hall, New York, pp. 5-28.

Dijkerman, H. J., J. M. B. Groot \& W. M. Herrebout, 1986. The parasitoids of the genus Yponomeuta Latreille (Lepidoptera, Yponomeutidae) in the Netherlands. Proceedings of the Koninklijke Nederlandse Akademie van Wetenschappen C 89: 379-398.

Doak, D. F., 1992. Lifetime impacts of herbivory for a perennial plant. Ecology 73: 2086-2099.

Dudt, J. F. \& D. J. Shure, 1994. The influence of light and nutrients on foliar phenolics and insect herbivory. Ecology 75: 86-98.

Forsberg, J., 1987. Size discrimination among conspecific hostplants in two pierid butterflies; Pieris napi L. and Pontia daplidice L. Oecologia 72: 52-57.

Fritz, R. S., 1990. Effects of genetic and environmental variation on resistance of willow to sawflies. Oecologia 82: 325-332.

Ganzhorn, J. U., 1995. Low-level forest disturbance effects on primary production, leaf chemistry, and lemur populations. Ecology 76: 2084-2096.

Grossmueller, D. W. \& R. C. Lederhouse, 1985. Oviposition site selection an aid to rapid growth and development in the tiger swallowtail butterfly, Papilio glaucus. Oecologia 66: 68-73.

Haukioja, E., 1991. The influence of grazing on the evolution, morphology and physiology of plants as modular organisms. Philosophical Transactions of the Royal Society of London B 333: 241-247.

Herrera, C. M., 1995. Floral biology, microclimate, and pollination by ectothermic bees in an early- blooming herb. Ecology 76: 218-228.

Jermy, T., 1993. Evolution of insect-plant relationships - a devil's advocate approach. Entomologia Experimentalis et Applicata 66: 3-12.

Joos, B., T. M. Casey, T. D. Fitzgerald \& W. A. Buttemer, 1988. Roles of the tent in behavioral thermoregulation of eastern tent caterpillars. Ecology 69: 2004-2011.

Juliano, S. A., 1988. Chrysomelid beetles on water lily leaves: herbivore density, leaf survival, and herbivore maturation. Ecology 69: 1294-1298.

Karban, R., 1992. Plant variation: its effects on populations of herbivorous insects. In: R. S. Fritz \& E. L. Simms (eds), Plant Res- istance to Herbivores and Pathogens. Ecology, Evolution, and Genetics. University of Chicago Press, Chicago, pp. 195-215.

Knapp, R. \& T. M. Casey, 1986. Thermal ecology, behavior, and growth of gypsy moth and eastern tent caterpillars. Ecology 67: 598-608.

Kooi, R. E., 1990. Host-plant selection and larval food-acceptance by small ermine moths. Thesis University of Leiden. Studies in Yponomeuta 9. ICG Printing, Dordrecht, The Netherlands.

Kooi, R. E., W. M. Herrebout \& T. P. M. van de Water, 1989. Observations on pupal and imaginal weights of small ermine moths (Lepidoptera: Yponomeuta). Proceedings of the Koninklijke Nederlandse Akademie van Wetenschappen C 92: 81-88.

Kuhlmann, U., 1995. Impact of insect predators and parasitoids on populations of the apple ermine moth, Yponomeuta malinellus (Lepidoptera: Yponomeutidae). PhD thesis. International Institute of Biological Control, IIBC European Station.

Leather, S. R., 1988. Size reproductive potential and fecundity in insects: things aren't as simple as they seem. Oikos 51: 386-389.

Leather, S. R. \& G. A. Mackenzie, 1994. Factors affecting the population development of the bird cherry ermine moth, Yponomeuta evonymella (L.). The Entomologist 113: 86-105.

Lincoln, D. E. \& H. A. Mooney, 1984. Herbivory on Diplacus aurantiacus shrubs in sun and shade. Oecologia 64: 173-176.

Littell, R. C., R. J. Freund \& P. C. Spector, 1991. SAS System for Linear Models. SAS Institute Inc., Cary, North Carolina.

Manly, B. F. J., 1991. Randomization and Monte Carlo methods in Biology. Chapman \& Hall, London.

Maiorana, V. C., 1981. Herbivory in sun and shade. Biological Journal of the Linnean Society 15: 151-156.

Marquis, R. J., 1988. Intra-crown variation in leaf herbivory and seed production in striped maple, Acer pennsylvanicum L. (Aceraceae). Oecologia 77: 51-55.

Mead, R., 1988. The Design of Experiments: Statistical Principles for Practical Applications. Cambridge University Press, Cambridge, UK.

Moore, L. V., J. H. Myers \& R. Eng, 1988. Western tent caterpillars prefer the sunny side of the tree, but why?. Oikos 51: 321-326.

Noreen, E. W., 1989. Computer Intensive Methods for Testing Hypothesis. John Wiley \& Sons, New York.

Nylin, S., N. Janz \& N. Wedell, 1996. Oviposition plant preference and offspring performance in the comma butterfly: correlations and conflicts. Entomologia Experimentalis et Applicata 80: 141144.

Ohsaki, N. \& Y. Sato, 1994. Food plant choice of Pieris butterflies as a trade-off between parasitoid avoidance and quality of plants. Ecology 75: 59-68.

Price, P. W., I. Andrade, C. Pires, E. Sujii \& E. M. Vieira, 1995. Gradient analysis using plant modular structure: pattern in plant architecture and insect herbivore utilization. Environmental Entomology 24: 497-505.

SAS Institute, 1989. SAS/STAT User's Guide Version 6. Vols 1-2. SAS Institute, Cary, North Carolina.

Schultz, J. C., 1983. Habitat selection and foraging tactics of caterpillars in heterogeneous trees. In: R. F. Denno \& M. S. McClure (eds), Variable Plants and Herbivores in Natural and Managed Systems. Academic Press, New York, pp. 61-90.

Sillén-Tullberg, B. \& O. Leimar, 1988. The evolution of gregariousness in distasteful insects as a defense against predators. The American Naturalist 132: 723-734.

Sokal, R. R. \& F. J. Rohlf, 1981. Biometry. The Principles and Practique of Statistics in Biological Research, (2nd edition). W. H. Freeman, New York. 
Stamp, N. E., 1980. Egg deposition patterns in butterflies: why do some species cluster their eggs rather than deposit them singly. The American Naturalist 115: 367-380.

Stamp, N. E., 1993. A temperate region view of the interaction of temperature, food quality, and predators on caterpillar foraging. In: N. E. Stamp \& T. M. Casey (eds), Caterpillars: Ecological and Evolutionary Constraints on Foraging. Chapman \& Hall, New York. pp. 479-508.

Stamp, N. E. \& M. D. Bowers, 1990. Variation in food quality and temperature constraint foraging of gregarious caterpillars. Ecology 71: 1031-1039.

Suomela, J. \& A. Nilson, 1994. Within-tree and among- tree variation in growth of Epirrita autumnata on mountain birch leaves. Ecological Entomology 19: 45-56.

Suomela, J., P. Kaitaniemi \& A. Nilson, 1995a. Systematic withintree variation in mountain birch leaf quality for a geometrid, Epirrita autumnata. Ecological Entomology 20: 283-292.

Suomela, J., V. Ossipov \& E. Haukioja, 1995b. Variation among and within mountain birch trees in foliage phenols, carbohydrates and amino acids, and in growth of Epirrita autumnata larvae. Journal of Chemical Ecology 21: 1421-1446.
Taylor, F., 1981. Ecology and evolution of physiological time in insects. The American Naturalist 117: 1-23.

Tullberg, B. S. \& A. F. Hunter, 1995. Evolution of larval gregariousness in relation to repellent defenses and warning coloration in tree-feeding Macrolepidotera: a phylogenetic analysis based on independent contrast. Biological Journal of the Linnean Society 57: 253-276

Van Driesche, R. G., T. S. Bellows, J. S. Elkinton, J. R. Gould \& D. N. Ferro, 1991. The meaning of percentage parasitism revisited: solutions to the problem of accurately estimating total losses from parasitism. Environmental Entomology 20: 1-7.

Watson, M. A., 1986. Integrated physiological units in plants. Trends in Ecology and Evolution 1: 119-123.

Williams, E. H., 1981. Thermal influences on oviposition in the montane butterfly Euphydryas gillettii. Oecologia 50: 342-346.

Williams, K. S., 1983. The coevolution of Euphydryas chalcedona butterflies and their larval host plants. III. Oviposition behaviour and host plant quality. Oecologia 56: 336-340.

Zangerl, A. R. \& M. R. Berenbaum, 1993. Plant chemistry, insect adaptations to plant chemistry, and host plant utilization patterns. Ecology 74: 47-54. 